been suggested in this discussion offer an explanation of this very remarkable circumstance. From the chemical point of view, such an interpretation seems more natural than any form of target theory.

${ }^{1}$ Hinshelwood, C. N., Nature, 166, 1089 (1950)

${ }^{2}$ Caldwell, P. C., and Hinshelwood, C. N., J. Chem. Soc., 3156 (1950).

${ }^{s}$ Caldwell, P. C., and Hinshelwood, C. N., J. Chem. Soc., 158 (1951)

4 Hevesy, G., Cold Spring Harbor Symp. Quant. Biol, 13, 129 (1948)

${ }^{5}$ See, for example, Clark, A. J., "General Pharmacology",

${ }^{6}$ Crowther, J. A., Proc. Roy. Soc., B, 100, 390 (1926). Lea, D. E., Haines, R. B., and Coulson, C. A., Proc. Roy. Soc., B, 120, 47 (1936) ; ibid., 123, 1 (1937). Lea, D.

: Tatum, E. L., Cold Spring Harbor Symp. Quant. Biol., 11, 278 (1946). Gray, C. H., and Tatum, E. L., Proc. U.S. Nat. Acad. Sci., 30, 404 (1944).

'See, for example, Liñdemann, F. A., Phil. Mag., 30, 560 (1915).

${ }^{\circ}$ See especially Clark, A. J., loc. cit.

${ }^{10}$ Fraser, D., Nature, 167, 33 (1951).

11 Hollænder, A., Stapleton, G. E., and Martin, F. I., Nature, 167, $103(1951)$

\section{EDINBURGH MEETING OF THE BRITISH ASSOCIATION}

$\mathrm{T}$ HE 113th meeting of the British Association will be held in Edinburgh during August 8-15. This will be the sixth time the members have met there. The first meeting was so early as 1834, and the most recent the meeting of 1921 . Edinburgh's connexion with the Association goes back even earlier than 1834, for the first suggestion for the formation of such a body was made by Sir David Brewster in an article in the Quarterly Review, and in 1831 he was one of its chief originators.

The president this year is H.R.H. the Duke of Edinburgh. On two previous occasions a member of the royal family has presided at a meeting of the Association : at the Oxford meeting of 1926 the Duke of Windsor (then Prince of Wales), and at the Aberdeen meeting ninety-two years ago the Prince Consort, whose name recalls at once the Great Exhibition of 1851, the centenary of which we are this year celebrating in the Festival of Britain. In a sense, indeed, this year's British Association meeting will be a part of the Festival.

The inaugural meeting will take place in the MeEwan Hall on the Wednesday evening, when the Duke of Edinburgh will deliver his presidential address on "The British Contribution to Science and Technology in the Past Hundred Years". Before the address, the president will receive from the University the honorary degree of doctor of laws. The proceedings will be relayed to an overflow meeting in the Usher Hall.

The retrospect of the past hundred years will be one theme (but by no means the only theme) running through the week, and several presidents of sections propose to speak of a century of their special subject (and Sir Claude Gibb in Section G on "Two Thousand Years of Engineering"!). Most, however, are looking forward as well as backward, like Sir Hector Hetherington in Section L ("Retrospect and Prospect"), or Sir Cyril Hinshelwood in Section B ("Chemistry at the Midcentury").

Scotland and Scottish subjects naturally take a prominent place in the programmes. Dr. D. A. Allan will lecture on "The Scottish Scene", there are papers on Scottish population, on the movement of miners, on the geology of the Lower Forth and the Scottish metamorphic and granitic rocks, on Celtic art, and other Scottish topics. Just as, last year, Birmingham was anxious to let it be known that parts of the Black Country are quite green, so this year Edinburgh is anxious to make it clear that she is not distinguished only for learning and law, but is also now an important industrial centre, as the list of excursions to factories shows. Other excursions range over half of Scotland, to Loch Sloy, the Tummel, the Bass Rock, Strathyre and (after the meeting) a geological field-trip to the Mull of Kintyre. These are only a few.

There are to be, as usual, several joint sessions of two Sections, for example, Physiology and Chemistry, to discuss "Hormones of the Pituitary"; and what is not usual, a whole-day joint meeting of no fewer than nine sections to discuss surveys of underdeveloped areas.

The three evening discourses are by the Very Rev. John Baillie on "The Impersonality of Science as a Diseipline for the Spiritual Life" ; by Sir Edward Salisbury on "The Contemplative Gardener" (surely a charming title); and by Prof. John Read on "Alchemy and Alchemists", which is charming in another sense, for it is believed that Prof. Read will play records of medieval charms, sung by a choir of St. Andrews students. These are, it is said, the words and their tunes once used by magicians to turn rivals into toads, or base metals into gold. We understand, however, that no untoward events occurred at the rehearsals-no toads, and, alas, no gold.

Another lecture will be about a modern magician-Sir Edmund Whittaker's lecture on Eddington's principles in the philosophy of science. It is not so very far from abracadabra to the mysterious numerical relationships of physical measurements; and we have, after all, actually transmuted metals. There will, by the way, be a discussion in Section $\mathbf{A}$ on "Nuclear Physics in Scotland".

Sessions likely to be found intensely interesting by specialists include one on probability in Section A*, $^{*}$ on the storage of farm products in Section M, and on advances in taxonomy in Section $K$. Section $J$ is devoting four meetings to "Current Trends in British Psychology : Occupational, Social, Educational, and Clinical". At an open meeting on the evening of August 13, the Division for Social and International Relations of Science will deal in particular with the international effects of radio communication and of travel by air.

All meetings are within a few minutes walk of each other and of the Old Quadrangle: and there are arrangements for lunches and teas, though Edinburgh can scarcely vie with 1834 , when a preliminary paragraph in The Scotsman said: "We hear the ordinaries are to be brilliantly attended. Contributions of venison and game have been received from various quarters, and fat bucks from both sides of the Border have been submitted for scientific discussion." On the social side, there will be a civic reception on the Thursday evening (August 9 ), and a University reception on Saturday evening (August 11), numerous section dinners, the Council's dinner for overseas and local guests, a conversazione by invitation of the scientific societies in Edinburgh, and a smaller reception by the Royal Society of Edinburgh. The president of the Royal Scottish Geographical Society and Mrs. Bartholomew are giving a garden party at Inveresk.

On Sunday morning (August 12) there will be a special service in St. Giles' Cathedral, conducted by the Very Rev. Charles Warr, minister of St. Giles' 
and Dean of the Chapel Royal in Scotland and of the Order of the Thistle. The sermon will be preached by Prof. Donald M. Baillie, of the University of St. Andrews. Representatives of the City and of the University will also be present.

A list of the sectional presidents and the titles of their addresses appeared in Nature of April 7, p. 547.
Further information can be obtained from the Secretary of the British Association, Burlington House, Piccadilly, London, W.1, or from the Local Secretaries, 3, Buccleuch Place, Edinburgh, 8. A provisional programme is already available, and a full programme giving detailed arrangements will be published about July 10.

\section{NEWS and VIEWS}

\section{Royal Society: Election of Foreign Members}

ThE following have been elected foreign members of the Royal Society : Prof. Herbert McLean Evans (Berkeley, Cal.), distinguished for his researches in anatomy, embryology and particularly in the field of experimental endocrinology; Prof. Karl Spencer Lashley (Cambridge, Mass.), distinguished for his studies of the neurological basis of animal behaviour and of the factors involved in learning; Dr. Carl Fredrik Störmer (Oslo), distinguished for his researches on the motion of charged particles in magnetic fields and on auroral phenomena; and Dr. Ralph Walter Graystone Wyckoff (Bethesda, Md.), distinguished for his contributions to the study of viruses.

\section{Forestry at Edinburgh :}

Prof. E. P. Stebbing

IT has recently been announced that Prof. E. P. Stebbing will retire from the ehair of forestry in the University of Edinburgh at the end of the current session. Thus will terminate a very remarkable record in university forestry teaching, as Prof. Stebbing became the lecturer in forestry more than forty years ago when in 1910 he succeeded Colonel Bailey ; in 1920 the lectureship was raised to a chair, with Prof. Stebbing as the first occupant. He went to Edinburgh from India after seventeen years of work in the Indian Forest Service, having devoted most of the latter part of that time to entomology. Although entomological work was gradually crowded out after his return to Great Britain, he has always retained very great interost in Indian forestry, and we owe to him an outstandingly valuable history of the forests of India, a very large undertaking in three volumes, aggregating nearly 1,900 pages. Prof. Stebbing has long been a very ardent advocate of the conservation of vegetation for the protection of soil and water supply, and has taken an active part in directing public attention to the consequences of denudation by overgrazing and injudicious clearing for cultivation, particularly on desert fringes such as those of the Sahara. This interest, together with his Indian experience of forest organization, protection and management, may be said to have provided the keynotes of his teaching, with his very wide firsthand knowledge of the forests of several continents. The outstanding features of his methods would appear to be the stress laid on some of the practical aspects of the professional forester's work, such as engineering and surveying, and on the value of what might be termed the orthodox or Continental working plan for management; he has not been in favour of any extension of the fundamental scientific training which would involve lengthening the course or displacing items of the established undergraduate syllabus. As a teacher, Prof. Stebbing's influence on forestry must have been comparable with that of his own instructor, William Schlich, particularly in Great Britain and in the Colonies, in view of the large numbers of forestry students who have passed through his hands over so long a period.

\section{Rumford Premium of the American Academy of} Arts and Sciences: Dr. H. E. Ives

The American Academy of Arts and Sciences has awarded the Rumford Premium for 1951 to Dr. Herbert E. Ives, of Upper Montclair, New Jersey. The Premium was founded by the Academy in honour of the American-born scientific worker, Benjamin Thompson, Count Rumford, and is awarded every second year in recognition of important discoveries in heat and light. Dr. Ives was with the Bell Telephone Laboratories during 1919-47 and has made outstanding contributions to optics, including the first accurate determination of the visibility function of the average human eye, scientific methods of colour measurement and specification, and other developments in the physics of light measurement. His practical applications in photo-electricity include the development in the Bell Telephone Laboratories of a method of sending photographs over telephone lines, now in general use by newspapers, and a demonstration (in 1927) of television over long dis. tances by wire and radio. Dr. Ives is a former president of the Optical Society of America and a vice-president of the American Association for the Advancement of Science.

\section{Optical Society of America : Honorary Members}

THE Optical Society of America announces in the editorial to the February number of the Society's Journal $(41,63$; 1951) that Profs. R. A. Millikan and A. Sommerfeld have been elected to honorary membership of the Society. In the citations it is stated thet Prof. Millikan's most important contributions to optics have been in the photo-electric determination of Planck's constant and in the extension of spectral measurements by the condensed spark vacuum spectrograph. $\mathrm{He}$ is best known for his work on the photo-electric effect and on the electronic charge, for which he received the Nobel Prize in 1923. Perhaps not so well known is that he, together with C. R. Mann, in 1902, first translated Drude's "Theory of Optics" into English. For Prof. A. Sommerfeld, emeritus professor of theoretical physics in the University of Munich, who is now in his eighty-fourth year and still continues to be active in scientific work, his classic book "Atombau und Spektrallinien" is quoted as sufficient evidence for the award, though mention is also made of several, among a very long list, of famous physicists who have been his pupils at one time or another.

\section{Museums of Nature and Man}

Dr. A. E. PARr, director of the American Museum of Natural History, New York, introduced a stimulating discussion at the recent biennial conference of 